\title{
Cigarette smoking among female students in five medical and nonmedical colleges
}

This article was published in the following Dove Press journal:

International Journal of General Medicine

20 August 2013

Number of times this article has been viewed

\author{
Hamza M Abdulghani' \\ Norah A Alrowais ${ }^{2}$ \\ Ali I Alhaqwi ${ }^{3}$ \\ Ahmed Alrasheedi ${ }^{2}$ \\ Mohammed Al-Zahir ${ }^{2}$ \\ Ahmed Al-Madani ${ }^{2}$ \\ Abdulaziz Al-Eissa ${ }^{2}$ \\ Bader Al-Hakmi \\ Redwan Takroni² \\ Farah Ahmad' \\ 'Department of Medical Education, \\ ${ }^{2}$ Department of Family and \\ Community Medicine, King Saud \\ University, ${ }^{3}$ Department of Family \\ Medicine, King Saud bin Abdulaziz \\ University for Health Sciences, Riyadh, \\ Saudi Arabia
}

Correspondence: Hamza Mohammad Abdulghani

Department of Medical Education,

College of Medicine, King Saud

University, PO Box 230155,

Riyadh I I32I, Saudi Arabia

Tel +966 I46 99I 77

Fax+966 I4671967

Email hamzaabg@gmail.com
Objectives: This study was conducted to determine the prevalence of smoking, knowledge about the ill effects of smoking on health, and the influence of family members' smoking habits among Saudi female students.

Methods: This is a type of cross-sectional study. A sample of 1,070 female students was selected by a nonrandom and convenient sampling method from five colleges (Medicine, Business and Administration, Computer Sciences, Education, and Languages and Translation) of King Saud University, Riyadh, Saudi Arabia. A self-administrated questionnaire was used to determine the personal, social, and educational characteristics of the respondents. In addition, questions about their smoking types, status, duration of smoking, knowledge about the ill effects of smoking, daily cigarette consumption, and reasons for quitting smoking were included.

Results: The students' response rate was $85 \%$. The prevalence of current smoking was $4.3 \%$ and $5.6 \%$ for cigarettes and water-pipes, respectively, whereas $3.9 \%$ of the participants were ex-smokers. The prevalence of current smoking was highest in the College of Business and Administration (10.81\%) and lowest in the College of Medicine (0.86\%). The majority (77\%) of the smokers' parents (current and ex-smokers) were also smokers. More than half (54\%) of the smokers started their smoking habit for entertainment, and $44.4 \%$ of the participants did not know that smoking causes serious health problems. The most common factors for quitting smoking were health concerns (54\%), religious beliefs (29\%), and parent's advice (17\%).

Conclusion: The study concludes that the prevalence of smoking varies in different subject streams and that family and friends have a great influence on individuals starting or stopping smoking. Extensive health education programs are needed to educate young women on the health hazards of smoking and help stop them from smoking.

Keywords: smoking prevalence, quitting smoking, female students, cigarettes per day

\section{Introduction}

Smoking is a major, preventable cause of morbidity and mortality. It kills nearly 6 million people worldwide each year. If the current trend continues, by 2030 , tobacco will kill more than 8 million people worldwide each year. Over the course of the 21 st century, tobacco use could kill a billion people or more. ${ }^{1-3}$ It is associated with a wide range of diseases, such as pulmonary, gastrointestinal and cardiovascular diseases, and various kinds of cancers. ${ }^{4,5}$ To further worsen the situation, the majority of smokers start their destructive habit before the age of 18 years. ${ }^{5,6}$ For all these reasons, the prevention and treatment of tobacco addiction have been targeted by the World Health Organization as priorities for intervention, especially in developing countries. ${ }^{7}$

The Saudi Arabian culture is based on Islamic Shari'ah rules, in which tobacco smoking is considered unacceptable behavior among both sexes but is deemed more 
unacceptable among women. Despite this fact, several studies conducted during the last 20 years have shown that the tobacco epidemic is firmly established in the Kingdom of Saudi Arabia. However, only a few studies have been conducted involving the Saudi female population. In recent years, some studies have been conducted in Saudi Arabia to investigate the patterns and potential predictors of tobacco consumption among the young, particularly among women. ${ }^{8-13}$ Earlier studies have reported that the prevalence of smoking ranges from 13\%-20\% among male and from 9\%-11\% among female university students, but the prevalence is much lower than that seen in other countries belonging to the Gulf Cooperation Council. ${ }^{8-13}$

A further increase in women smoking is expected in upcoming years, as more and more educated women are choosing to work. ${ }^{14,15}$ Studies conducted in Australia and other developed countries have shown that working women have increased levels of stress because their working hours have been increased in the office as well as in the home, and one reason that women smoke is to cope with stress. ${ }^{14,15}$ Other reasons for smoking that have been reported include gender equality and economic factors. ${ }^{16}$

Female smoking increases with age, which may be attributed to the recent social independence attained by moneyearning women in traditional societies. ${ }^{17}$ Tobacco industries promote cigarettes to women using seductive but false images of vitality, slimness, modernity, emancipation, sophistication, and sexual allure. ${ }^{18}$ In reality, smoking causes disease and death. Tobacco companies have now produced a range of brands aimed at women. Most notable are the "women-only" brands; these "feminized" cigarettes are long, extra-slim, low-tar, light-colored, or have menthol added. ${ }^{18}$

During the last two decades, studies have reported a firmly established tobacco epidemic in the Kingdom of Saudi Arabia. ${ }^{10,13,19}$ The amount of tobacco products imported into the kingdom has increased 40 times (from 1,061 to 41,440 tons) during a period of 30 years; unfortunately, this figure is still continuously increasing. ${ }^{20}$

The Saudi government is spending billions of dollars to counter the prevalence of smoking. ${ }^{21}$ Smoking-related literature has shown that in the last 10 years, the highest prevalence of smoking has been found among women aged between 20 and 24 years (mostly university students). ${ }^{22}$ An extensive literature review of smoking data from the Gulf countries also found that most of the studies were limited to investigation of prevalence, predictors, and patterns of smoking among healthy populations and concluded with strategies and recommendations for prevention and further research. ${ }^{22}$ However, only a few studies have been conducted to estimate the prevalence of smoking among Saudi female university students, ${ }^{10,12,13}$ and most of them failed to explore in-depth the women's awareness and attitude toward smoking. The smoking behaviors of college students can provide valuable information about smoking trends among young adults, and such information can help to create a tailored approach to tobacco control.

The present study appraises the prevalence and types of smoking, assesses the knowledge and effects of smoking on health, evaluates the influence of family and friends' smoking habits, and determines the factors influencing smoking behavior and knowledge about its adverse health effects among female students of the five colleges of King Saud University (KSU), Riyadh, Saudi Arabia.

\section{Materials and methods Place and duration of the study}

The study was conducted in the Department of Medical Education, College of Medicine, KSU, Riyadh, Saudi Arabia, from August 2012-November 2012 (16 weeks). Data collection was performed over the course of 4 weeks during this period and covered five KSU colleges (Medicine, Education, Languages and Translation, Business Administration, and Computer Sciences).

\section{Study design and data collection tool}

The study followed a cross-sectional design. A selfadministrated questionnaire was developed after an extensive literature review process. Group discussion was carried out with all coauthors to brainstorm, which resulted in a suitable data collection tool. For initial data collection, a selfadministered questionnaire was finalized after the group discussion. This was further modified by consulting with other experts in the field. The modified questionnaire was piloted on 20 participants for further finalization, depending on the feedback from the pilot study. The final validated questionnaire contained twelve items assessing tobacco use history and related factors. The first five questions were directed to all participants, including smokers, nonsmokers, and ex-smokers, and sought information related to age, presence of smoking in the family, knowledge of tobacco effects, and attitude toward smoking. The next seven questions were directed to smokers and ex-smokers only. These items assessed types of smoking (water-pipe or cigarette), the amount of smoking (number of cigarettes per day [CPD] or water-pipes per week), age of initiation (age when first cigarette or water-pipe was smoked), reason for initiation (eg, social pressure, entertainment, etc), history of quitting 
or trying to quit smoking, and the reason for quitting (see questionnaire under the 'Supplementary materials').

\section{Data collection procedure}

An anonymous, self-administered questionnaire was distributed to 1,070 female students of different educational levels attending the five colleges of KSU who agreed and gave consent to participate in the survey. A nonrandom, convenient sampling technique was employed to collect the data because smoking among young women is a sensitive issue according to the Saudi cultural perspective.

\section{Statistical analysis}

Collected data were entered in Excel 2007 (Microsoft Corporation, Redmond, WA, USA) and analyzed using the SPSS program (version 18.0; IBM Corporation, Armonk, NY, USA). Descriptive statistics (mean, standard deviation, and percentages) were used for summarizing the study and outcome variables. Pearson's chi-square test and odds ratios with 95\% confidence intervals were used for observing and quantifying the association between smoking and different study variables.

\section{Ethical aspects}

All participants were informed about the objectives of the study, and the need for information about the items in the questionnaire was explained. The study was approved by the research ethical committee of the College of Medicine, KSU.

\section{Results}

A total of 907 of 1,070 female students completed and returned the questionnaire, for a response rate of $85 \%$. Among the respondents, $4.3 \%$ were current cigarette smokers, $5.6 \%$ were water-pipe smokers, and $3.9 \%$ were ex-smokers. The prevalence of smoking (including both current and ex-smokers) was $19.46 \%$ in the College of Business and Administration compared with $9.69 \%$ in the College of Languages and Translation. The lowest prevalence of current and ex-smokers was $2.14 \%$ in the College of Medicine (Table 1). Various demographic factors that affect smoking habits were checked in all the smokers (water-pipe, current, and ex-smokers). More than half (54\%) of the study participants started their smoking habit in their college study period; the remaining population (46\%) started smoking at the high school or intermediate school levels. The most common cause of starting smoking was entertainment (54\%) and to get relief from psychological pressures (29.4\%; Table 2$)$.
Table I Prevalence of smoking among female students in the five colleges of King Saud University

\begin{tabular}{|c|c|c|c|c|}
\hline \multirow[t]{2}{*}{ College name } & \multicolumn{4}{|c|}{ Smoking status (number and \%) } \\
\hline & Sample & $\begin{array}{l}\text { Current } \\
\text { smokers }\end{array}$ & $\begin{array}{l}\text { Previous } \\
\text { smokers }\end{array}$ & Total \\
\hline Business and & $185(20.4)$ & $20(10.81)$ & $16(8.65)$ & $36(19.46)$ \\
\hline \multicolumn{5}{|l|}{ Administration } \\
\hline Languages and & $165(18.2)$ & $7(4.24)$ & $9(5.45)$ & $16(9.69)$ \\
\hline \multicolumn{5}{|l|}{ Translation } \\
\hline Education & $140(15.4)$ & $7(5)$ & $2(1.43)$ & $9(6.43)$ \\
\hline Computer & $184(20.3)$ & $3(1.63)$ & $5(2.7 I)$ & $8(4.35)$ \\
\hline \multicolumn{5}{|l|}{ Sciences } \\
\hline Medicine & $233(25.7)$ & $2(0.86)$ & $3(1.28)$ & $5(2.14)$ \\
\hline Total & $907(100)$ & $39(4.3)$ & $35(3.9)$ & $74(8.2)$ \\
\hline
\end{tabular}

Note: Both cigarette and water-pipe smokers are combined.

The majority (77\%) of the participants responded that they were inspired to smoke by a family member or family members, whereas $19 \%$ of participants were influenced either by friends or the media.

The majority of the participants (69\%) smoked $10 \mathrm{CPD}$, and $18 \%$ of the participants smoked from more than 10 to $20 \mathrm{CPD}$; a small number of participants (7\%) smoked

Table 2 Different demographic characters identified through this study that affect smoking habit among female students

\begin{tabular}{|c|c|c|c|c|}
\hline \multirow{3}{*}{$\begin{array}{l}\text { Demographic } \\
\text { characteristics }\end{array}$} & \multicolumn{2}{|l|}{ Smoking } & \multirow[t]{3}{*}{ Total } & \multirow{3}{*}{$\begin{array}{l}\text { Odds ratio } \\
\text { (95\% } \\
\text { confidence } \\
\text { interval) }\end{array}$} \\
\hline & Yes & No & & \\
\hline & $\mathbf{N}(\%)$ & $\mathbf{N}(\%)$ & & \\
\hline \multicolumn{5}{|l|}{ Age, year } \\
\hline$\leq 18$ & $34(8.1)$ & 384 (91.9) & $418(100)$ & 1.0 \\
\hline$>18$ & $40(8.8)$ & $4 \mid 4$ (9I.2) & $454(100)$ & $\begin{array}{l}1.09 \\
(0.66-1.81)\end{array}$ \\
\hline Total & $74(8.5)$ & 798 (91.5) & $872(100)$ & \\
\hline \multicolumn{5}{|l|}{ School status } \\
\hline Before college & $34(8.1)$ & 384 (91.9) & $418(100)$ & 1.0 \\
\hline College & $40(8.8)$ & $4 \mid 4$ (9I.2) & $454(100)$ & $\begin{array}{l}1.09 \\
(0.66-1.81)\end{array}$ \\
\hline Total & $74(8.5)$ & 798 (9I.5) & $872(100)$ & \\
\hline \multicolumn{5}{|l|}{ Inspired addiction } \\
\hline Family & $57(8.1)$ & $64 \mid$ (9I.9) & $698(100)$ & 1.0 \\
\hline Friends/media & $17(9.9)$ & $155(90.1)$ & $172(100)$ & $\begin{array}{l}1.23 \\
(0.67-2.25)\end{array}$ \\
\hline Total & $74(8.5)$ & 796 (9I.5) & $870(100)$ & \\
\hline \multicolumn{5}{|l|}{ Reason } \\
\hline Entertainment & $40(8.1)$ & 449 (91.9) & $489(100)$ & 1.0 \\
\hline Distress/others & $34(8.1)$ & 384 (91.9) & $418(100)$ & $\begin{array}{l}0.99 \\
(0.6-1.6)\end{array}$ \\
\hline Total & $74(8.1)$ & 834 (91.9) & $907(100)$ & \\
\hline \multicolumn{5}{|l|}{ Family income } \\
\hline Average/low & $35(12.9)$ & $237(87.1)$ & $272(100)$ & 1.0 \\
\hline High & $39(8.6)$ & $4 \mid 5(9 \mid .4)$ & $454(100)$ & $\begin{array}{l}0.6 \\
(0.38-1.1)\end{array}$ \\
\hline Total & $74(10.2)$ & $652(89.8)$ & $726(100)$ & \\
\hline
\end{tabular}


more than 20 or fewer than 10 CPD (Figure 1). About $26 \%$ of the study participants had one or more family members who were smokers, mostly students' fathers (10.5\%) and brothers (14\%), and rarely (1.5\%), students' husbands, grandfathers, or uncles. Among all the smoking participants (both current and previous smokers), nearly $57 \%$ of the participants' family members were smokers (Table 2).

Pearson's chi-square test did not show an association of smoking with other study variables, with an odds ratio of 1.09 (95\% confidence interval, 0.66-1.6; Table 2). Surprisingly, almost half the participants were not aware of the adverse effects of smoking. Nearly $44 \%$ of the respondents did not know that smoking has been linked with depression and its symptoms, such as laziness and inertia. ${ }^{33}$ In addition, 64\% of the respondents thought that cigarette smoking was not associated with infertility, ${ }^{34}$ and a very small number of participants $(0.7 \%)$ were not aware that smoking causes lung cancer (Figure 2). The most common causes of quitting the smoking habit were health-related considerations (54.3\%). However, the other most common causes of quitting smoking among the female students were religious beliefs (29\%) and parent's advice (17\%).

\section{Discussion}

This study was conducted to determine the prevalence of tobacco smoking among Saudi female students studying at the five different colleges of KSU. It demonstrated that $4.3 \%$ of the participants were current smokers, which is in agreement with the results obtained from a local study involving adult women who visited primary health care centers in Riyadh city (4\%) and another study performed in Dammam city involving laboratory technician female students (4.4\%). ${ }^{23,24}$ Conversely, several international studies ${ }^{25-27}$ and local studies conducted in Saudi Arabia showed a higher prevalence of smoking in a similar group (11\%). ${ }^{9-13}$ These variations among the results could be easily explained by the accuracy of reporting by participants or just by cultural differences.

The water-pipe form of tobacco use, other than cigarettes, was the most commonly used smoking practice across the globe, including in Saudi Arabia. ${ }^{19}$ The Global Youth Tobacco Survey Collaborative Group 2005, in the Eastern Mediterranean Region, reported that water-pipe smoking is enjoying a great rise in popularity and becoming a behavioral norm, including for women. ${ }^{28} \mathrm{~A}$ local study among male medical college students in Riyadh, Saudi Arabia, showed a higher proportion of water-pipe users $(44 \%)$ than cigarette users (32.3\%). Possibly, this could be a result of the misconception that water-pipe smoking is less dangerous than smoking cigarettes. Instead, water-pipe smoking may bear larger risks to health ${ }^{28,29}$ and be even more detrimental because the plasma nicotine level resulting from smoking a single water-pipe is $20 \%$ greater than that resulting from smoking 21 cigarettes. $^{30}$

A study of female students at the College of Arts and Sciences, King Abdul Aziz University, Jeddah, Saudi Arabia, showed that nearly $11 \%$ of the respondents were current tobacco users. ${ }^{19}$ The same study also reported that the prevalence of cigarette and water-pipe smoking was 5\% and $8.7 \%$, respectively, whereas about $2.7 \%$ of the women were both cigarette and water-pipe smokers. ${ }^{19}$ In the College of Medicine, KSU, the prevalence of current tobacco smoking was $2.4 \% .^{10}$ Another study from the College of Applied Medical Sciences, Riyadh, showed the prevalence of smoking among university students to be $20 \%$ in men and $9 \%$ in women. ${ }^{20}$ Another international study from Ethiopia reported that $4.6 \%$ of female medical students smoke cigarettes. ${ }^{31}$

In this study, we found that up to $56 \%$ of the smokers were inspired to smoke by their parents or other family members. Other factors associated with female smoking

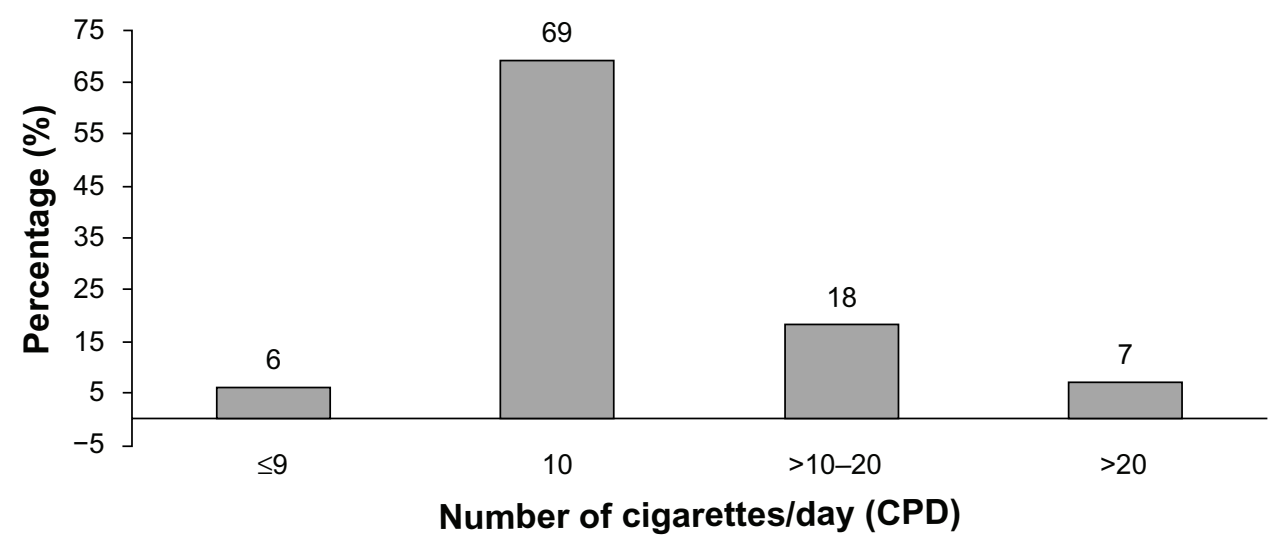

Figure I Number of cigarettes smoked/day among the studied smoker female population. 


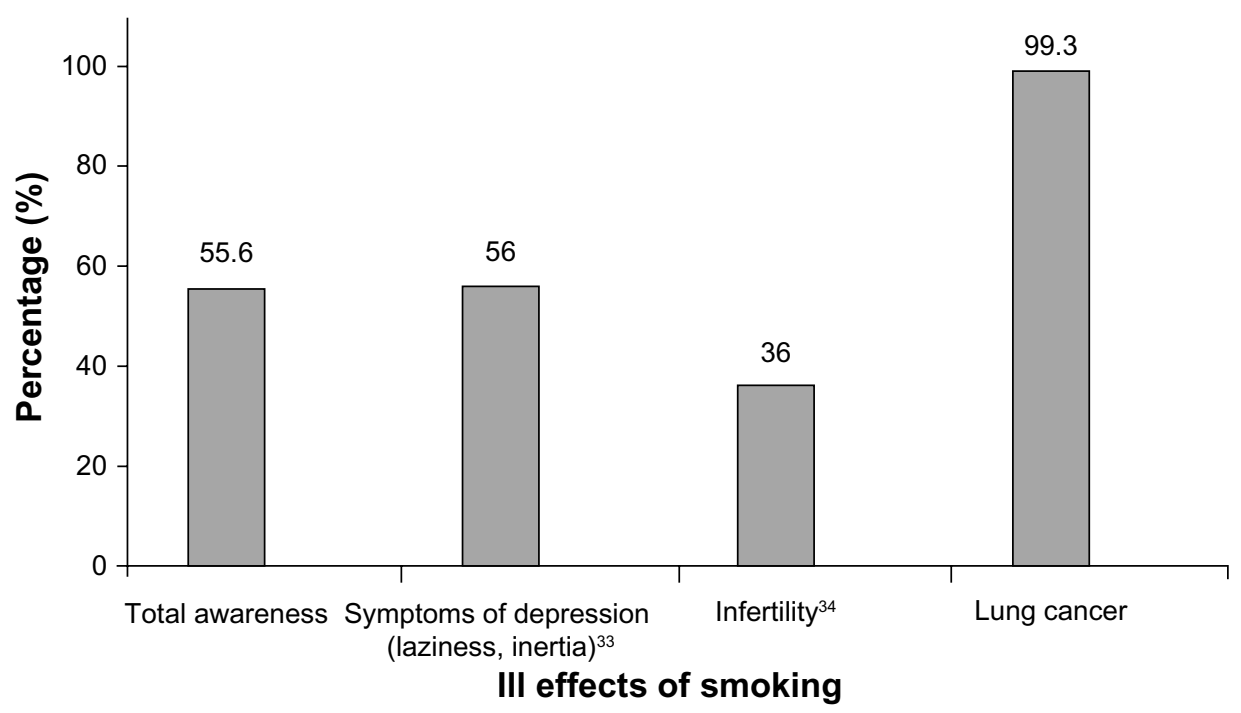

Figure 2 Awareness about the ill effects of smoking among female smokers.

were a smoking spouse, being a single mother, being younger than 34 years, not taking childcare leave, parents not alive, and nursery use. ${ }^{32}$

In addition, it was found that most of the smokers (54\%) started smoking for entertainment purposes only. Unfortunately, there is an evidence-based relation between smoking and depression, ${ }^{33}$ and it is recommended that this important fact should be communicated to the smokers through various means. Interestingly, getting relief from psychological pressures was considered by the participants to be the second most important reason to start tobacco smoking. The significant relationship between tobacco smoking and alleviation of stress has been reported by a local study conducted among medical students. ${ }^{34}$ University students and the public in general should be educated about other effective stress management strategies to help students encountering different kinds of stressors and to not have them rely on harmful behavior such as tobacco smoking for stress relief.

The responses of the participants reflect their low awareness and education about smoking and ill health, although a meta-analysis study has already proved a strong relation between the two. ${ }^{35}$

We found that the most important reason given for quitting smoking was health-related issues, which is consistent with that seen in other studies. ${ }^{22,33}$ Because this study was conducted in the university colleges, where women are receiving their education, it is reasonable to find health considerations to be their main reason. Another important reason given for quitting smoking was religious beliefs, which is quite reasonable in the Saudi religious community and has been already highlighted by many local and international reports. ${ }^{36,37}$ On the basis of the current findings, we suggest that this important reason for quitting smoking could be largely employed in a smoking prevention and health education program.

All associated factors identified for women's smoking were analyzed by Pearson's chi-square test, but the results were not significant from a statistical point of view, possibly because of the small number of smokers we found in this study. Hence, a case-control study is needed on a larger scale to identify the true association of the factors leading to the start of smoking. One of the major limitations of this study is that it used a self-administered questionnaire with a convenient (by the consent and willingness of students) sampling method. In addition, the response rate varied in different colleges. This may have affected the estimation of the prevalence of women smoking in some colleges taken into consideration, but the results were congruent with the findings of a study from a different university. ${ }^{31}$ However, results from medical colleges of other places (similar to the College of Medicine) showed a higher prevalence of smoking than the KSU's College of Medicine data obtained through this study. ${ }^{20}$ In reality, the individual colleges cannot be compared from one study to another because of variations in sample size. Furthermore, the compliance of students in answering the questionnaire and giving true information might not have been accurate, as the study dealt with sensitive issues regarding our preserved Saudi culture, especially in the female population. The response rate in our study (85\%) was unexpectedly good, and the results were consistent with other previous studies that were done in other cities in a similar 
population, ${ }^{23,24}$ which may reflect the cultural differences between the regions influencing the results.

\section{Conclusion}

On the basis of this study, we hypothesize that smoking is less prevalent among female students of different colleges in KSU. The amount of water-pipe smoking among the female smokers was higher than that of cigarette smoking (current and ex-smokers). One of the important factors influencing the participants to smoke was the presence of a smoker in the family. Hence, it is recommended that all family members should avoid smoking, at least in front of their offspring, as most adolescents look up to their parents as role-models.

The important factors identified for quitting smoking were health concerns and religious beliefs. Therefore, in a smoking prevention program, factors such as health and religious education should be considered and used to combat the expected future epidemic of smoking-related health problems. Systematic, organized, and mandatory stress coping programs should be implemented for all university students to help them in coping with psychological pressures and in minimizing the possibilities for using tobacco for relieving stress.

This study has certain limitations because of the use of the convenient sampling technique and because the sample size was very small, so multivariate analysis was not done to establish the correlation among different factors related to smoking. Hence, future studies with greater sample size with exhaustive statistical analysis of different variables responsible for, and of the type of, smoking are warranted. As smoking is quite prevalent in Saudi Arabia, all other forms of tobacco consumption should be addressed more in tobacco control programs, and health education programs should be promoted to raise the awareness about the health hazards of smoking.

\section{Acknowledgments}

We thank Dr Shaffi Ahmad Shaikh for helping with statistical analysis. We are grateful to Prof Riaz Qureshi for revising the manuscript. We also thank the teachers and students of the five participating colleges of KSU who helped in distribution of the questionnaire in their colleges and participated in this study. This work was funded by the College of Medicine, Research Center, Deanship of Scientific Research, King Saud University, Riyadh, Saudi Arabia.

\section{Disclosure}

The authors report no conflicts of interest in this work.

\section{References}

1. World Health Organization. WHO Report on the Global Tobacco Epidemic 2011: Warning About the Danger of Tobacco. Geneva: World Health Organization. Available from: http://www.who.int/tobacco/ global_report/2011/en/index.html. Accessed June 15, 2012.

2. Jha P, Ranson MK, Nguyen SN, Yach D. Estimates of global and regional smoking prevalence in 1995, by age and sex. Am J Public Health. 2002;92(6):1002-1006.

3. World Health Organization. Growing Up Without Tobacco. Geneva: World Health Organization; 1998. Available from: http://www.who. int/inf-pr-1998/en/pr98-42.html. Accessed June 24, 2012.

4. US Department of Health and Human Services. Reducing Tobacco Use: A Report of the Surgeon General. Atlanta, GA: Office on Smoking and Health; 2000.

5. Novotny TE, Giovino GA. Tobacco use. In: Brownson RC, Remington PL, Davis JR, editors. Chronic Disease Epidemiology and Control. Washington, DC: American Public Health Association; 1998:117-148.

6. Gezairy HA. Regional Director's Message. World No-Tobacco Day, May 31, 1998. Alexandria, VA: World Health Organization Regional Office for the Eastern Mediterranean; 1998.

7. Peto R, Lopez AD, Boreham J, Thun M, Heath C Jr. Mortality from tobacco in developed countries: indirect estimation from national vital statistics. Lancet. 1992;339(8804):1268-1278.

8. Ulin PR, Robinson E, Tolley EE. Qualitative Methods in Public Health: A Field Guide for Applied Research. San Francisco: Jossey-Bass; 2005.

9. Abdalla AM, Al-Kaabba AF, Saeed AA, Abdulrahman BM, Raat H. Gender differences in smoking behavior among adolescents in Saudi Arabia. Saudi Med J. 2007;28(7):1102-1108.

10. Al-Turki YA, Al-Rowais NA. Prevalence of smoking among female medical students in the College of Medicine, Riyadh, Saudi Arabia. Saudi Med J. 2008;29(2):311-312.

11. Jarallah JS, al-Rubeaan KA, al-Nuaim AR, al-Ruhaily AA, Kalantan KA. Prevalence and determinants of smoking in three regions of Saudi Arabia. Tob Control. 1999;8(1):53-56.

12. Felimban FM. The smoking practices and attitudes towards smoking of female university students in Riyadh. Saudi Med J. 1993;14: 220-224.

13. Azhar A, Alsayed N. Prevalence of smoking among female medical students in Saudai Arabia. Asian Pac J Cancer Prev. 2011;3(9): $4245-4248$.

14. Radi S, Ostry A, Lamontagne AD. Job stress and other working conditions: Relationships with smoking behaviors in a representative sample of working Australians. Am J Ind Med. 2007;50(8):584-596.

15. Richardson L, Greaves L, Jategaonkar N, Bell K, Pederson A, Tungohan E. Rethinking an assessment of nicotine dependence: a sex, gender and diversity analysis of the Fagerstrom Test for Nicotine Dependence. J Smoking Cessation. 2007;2(2):59-67.

16. Pampel FC. Global patterns and determinants of sex differences in smoking. Int J Comp Sociol. 2006;47(6):466-487.

17. Bin Ghouth AS, Bahaj AA. Prevalence and attitudes of smoking among secondary school teachers in Hadramout coastal districts, Yemen. Online J Health Allied Sci. 2006;5(2):1.

18. Mackay J. Immediate action required: Understanding the tobacco epidemic and stopping it in its tracks. Center for Communications, Health and the Environment (CECHE). Available from: http://www.ceche.org/ publications/infocus/spring2008/spring08-lead.html. Accessed April 20, 2012.

19. Merdad LA, Al-Zahrani MS, Farsi JM. Smoking habits among Saudi female university students: prevalence, influencing factors and risk awareness. Ann Saudi Med. 2007;27(5):366-369.

20. Siddiqui S, Ogbeide DO. Profile of smoking amongst health staff in a primary care unit at a general hospital in Riyadh, Saudi Arabia. Saudi Med J. 2001;22(12):1101-1104.

21. Haseebullah A, Lmotairi M. Smoking in Saudi Arabia and its control measures. Br J Humanities Social Sci. 2012;5(2):69-75. 
22. Al-Eisa I S, Al-Terkit AM, Radwan MM, Al-Jassar T, Al-Mutar MS Smoking among health care workers of the capital governorate health region, Kuwait: Prevalence and attitudes. Kuwait Med J. 2006;38(2): 100-106.

23. Aleissa EI. The frequency of health-related behaviors among Saudi adolescents visiting primary health care centers in Riyadh City. J Family Community Med. 2001;8(1):19-26.

24. Mandil AM, Bahnassy AA, Aboul-Azm SM, Bashawri LA. Knowledge, attitude and smoking patterns among nursing and laboratory technology students, Dammam, Saudi Arabia. J Family Community Med. 1999;6(2):51-58.

25. Durrah TL. Correlates of daily smoking among female arrestees in New York City and Los Angeles, 1997. Am J Public Health. 2005;95(10):1788-1792.

26. Warren CW, Jones NR, Eriksen MP, Asma S; Global Tobacco Surveillance System (GTSS) collaborative group. Patterns of global tobacco use in young people and implications for future chronic disease burden in adults. Lancet. 2006;367(9512):749-753.

27. Steptoe A, Wardle J, Cui W, et al. An international comparison of tobacco smoking, beliefs and risk awareness in university students from 23 countries. Addiction. 2002;97(12):1561-1571.

28. Maziak W, Ward KD, Afifi Soweid RA, Eissenberg T. Tobacco smoking using a waterpipe: a re-emerging strain in a global epidemic. Tob Control. 2004;13(4):327-333.

29. Maziak W, Rastam S, Eissenberg T, et al. Gender and smoking statusbased analysis of views regarding waterpipe and cigarette smoking in Aleppo, Syria. Prev Med. 2004;38(4):479-484.
30. Hadidi KA, Mohammed FI. Nicotine content in tobacco used in hubblebubble smoking. Saudi Med J. 2004;25(7):912-917.

31. Deressa W, Azazh A. Substance use and its predictors among undergraduate medical students of Addis Ababa University in Ethiopia. BMC Public Health. 2011;11:660.

32. Kubo S, Inoue T, Yamazaki A, Hata A. [Contribution of socioeconomic status to smoking behavior of parents of 4th grade elementary school students in Japan]. Nihon Koshu Eisei Zasshi. 2011;58(5):340-349. Japanese.

33. Duncan B, Rees DI. Effect of smoking on depressive symptomatology: a reexamination of data from the National Longitudinal Study of Adolescent Health. Am J Epidemiol. 2005;162(5):461-470.

34. Augood C, Duckitt K, Templeton AA. Smoking and female infertility: a systematic review and meta-analysis. Hum Reprod. 1998;13(6) $1532-1539$

35. Carter-Pokras OD, Feldman RH, Kanamori M, et al. Barriers and facilitators to smoking cessation among Latino adults. J Natl Med Assoc. 2011;103(5):423-431.

36. Gillum F, Obisesan TO, Jarrett NC. Smokeless tobacco use and religiousness. Int J Environ Res Public Health. 2009;6(1):225-231.

37. Kaholokula J. Culturally informed smoking cessation strategies for Native Hawaiians. Nicotine Tob Res. 2008;10(4):671-681. 


\section{Supplementary material}

Dear Student,

Thank you for your participation in this study. The study aims to help you and us to understand the importance of smoking and its related factors. Please try to answer the questions carefully and honestly. All information will be treated confidentially and your participation is voluntary; you have the right to withdraw your participation at any time.

College: (this was mentioned and specified before distribution)

1. Age: Years

2. Smoker in family?

A) Is there any smoker in your family YES $\square \quad \mathrm{NO}$

B) If yes, please specify:

Father $\square$ Mother $\square$ Brother $\square$ Sister $\square$ Other (specify)......

3. The following diseases are associated with the ill effects of smoking:

Oral cancer

YES $\square$ NO

Heart diseases

YES $\square$ NO

Lung disease

YES $\square$ NO

Blood pressure

YES $\square$ NO

Premature aging and wrinkles

YES $\square \quad$ NO

Infertility

YES $\square \quad$ NO

Symptoms of depression (laziness, inertia)

YES $\square \quad \mathrm{NO}$

Neurological disorders

YES $\square \quad$ NO

Complications in pregnancy

YES $\square \quad$ NO

Damage to digestive system

YES $\square \quad$ NO

4. Do you smoke?

YES $\square \mathrm{NO}$

5. If yes, are you: Current smoker $\quad \square \quad$ Ex-smoker

6. What type of smoking do you participate in?

7. What was the age when you started smoking?

8. At what level of school did you start smoking?

9. Why did you start smoking?

10. What is your family income?

11. How many cigarettes do you smoke per day?

12. For ex-smokers: Why did you quit smoking? Give reasons.

THANK YOU FOR YOUR COOPERATION 
International Journal of General Medicine

Dovepress

\section{Publish your work in this journal}

The International Journal of General Medicine is an international, peer-reviewed open-access journal that focuses on general and internal medicine, pathogenesis, epidemiology, diagnosis, monitoring and treatment protocols. The journal is characterized by the rapid reporting of reviews, original research and clinical studies across all disease areas.
A key focus is the elucidation of disease processes and management protocols resulting in improved outcomes for the patient. The manuscript management system is completely online and includes a very quick and fair peer-review system. Visit http://www.dovepress.com/ testimonials.php to read real quotes from published authors.

Submit your manuscript here: http://www.dovepress.com/international-journal-of-general-medicine-journal 